OPEN ACCESS

Edited by:

Sejin Im,

Sungkyunkwan University,

South Korea

Reviewed by:

Xionglin Fan,

Huazhong University of Science and

Technology, China

Thorsten Demberg,

Baylor College of Medicine,

United States

*Correspondence:

Jonas Herzberg

jonas.herzberg@krankenhausreinbek.de

${ }^{t}$ These authors share first authorship

Specialty section:

This article was submitted to Immunological Memory, a section of the journal

Frontiers in Immunology

Received: 20 December 2021 Accepted: 07 February 2022 Published: 04 March 2022

Citation:

Herzberg J, Fischer B, Lindenkamp C Becher $\mathrm{H}$, Becker AK, Honarpisheh $\mathrm{H}$, Guraya SY, Strate $T$ and Knabbe $C$ (2022) Persistence of Immune Response in Health Care Workers After Two Doses BNT162b2 in a Longitudinal Observational Study.

Front. Immunol. 13:839922. doi: 10.3389/fimmu.2022.839922

\section{Persistence of Immune Response in Health Care Workers After Two Doses BNT162b2 in a Longitudinal Observational Study}

\author{
Jonas Herzberg ${ }^{1 * \dagger}$, Bastian Fischer ${ }^{2 \dagger}$, Christopher Lindenkamp ${ }^{2}$, Heiko Becher ${ }^{3}$, \\ Ann-Kristin Becker ${ }^{4}$, Human Honarpisheh ${ }^{1}$, Salman Yousuf Guraya ${ }^{5}$, \\ Tim Strate ${ }^{1}$ and Cornelius Knabbe ${ }^{2}$ \\ ${ }^{1}$ Department of Surgery, Krankenhaus Reinbek St. Adolf-Stift, Reinbek, Germany, 2 Institut für Laboratoriums- und \\ Transfusionsmedizin, Herz- und Diabeteszentrum Nordrhein-Westfalen, Universitätsklinik der Ruhr-Universität Bochum, Bad \\ Oeynhausen, Germany, ${ }^{3}$ Institute of Medical Biometry and Epidemiology, University Medical Center Hamburg-Eppendorf, \\ Hamburg, Germany, ${ }^{4}$ Asklepios Klinik Harburg, Abteilung für Psychiatrie und Psychotherapie, Hamburg, Germany, ${ }^{5}$ Clinical \\ Sciences Department, College of Medicine, University of Sharjah, Sharjah, United Arab Emirates
}

Background: The mRNA-based vaccine BNT162b2 of BioNTech/Pfizer has shown high efficacy against SARS-CoV-2 infection and a severe course of the COVID-19 disease. However, little is known about the long-term durability of the induced immune response resulting from the vaccination.

Methods: In a longitudinal observational study in employees at a German hospital we compared the humoral and cellular immune response in 184 participants after two doses of the BioNTech/Pfizer vaccine (BNT162b2) with a mid-term follow-up after 9 months. Anti-SARS-CoV-2 binding antibodies were determined using both a quantitative and a semi-quantitative assay. For a qualitative assessment of the humoral immune response, we additionally measured neutralizing antibodies. Cellular immune response was evaluated by measuring Interferon-gamma release after stimulating blood-cells with SARS-CoV-2 specific peptides using a commercial assay.

Results: In the first analysis, a 100\% humoral response rate was described after two doses of BNT162b2 vaccine with a mean antibody ratio of 8.01 \pm 1.00 .9 months after the second dose of BNT162b2, serological testing showed a significant decreased mean antibody ratio of $3.84 \pm 1.69$ ( $p<0.001)$. Neutralizing antibodies were still detectable in $96 \%$ of all participants, showing an average binding inhibition value of $68.20 \% \pm 18.87 \%$. Older age $(p<0.001)$ and obesity $(p=0.01)$ had a negative effect on the antibody persistence. SARS-CoV-2 specific cellular immune response was proven in $75 \%$ of individuals (mean Interferon-gamma release: $579.68 \mathrm{mlU} / \mathrm{ml} \pm 705.56 \mathrm{mlU} / \mathrm{ml}$ ).

Conclusion: Our data shows a declining immune response 9 months after the second dose of BNT162b2, supporting the potentially beneficial effect of booster vaccinations, the negative effect of obesity and age stresses the need of booster doses especially in these groups.

Keywords: SARS-CoV-2, humoral and cellular immunity, health care worker, immunological memory, vaccination, BNT162b2 


\section{INTRODUCTION}

In order to fight the global coronavirus disease 2019 (COVID19) pandemic, a variety of vaccines were applied worldwide, beginning in December 2020, and were felt to be the pivoting point in this pandemic situation. The mRNA vaccines, provided by BioNTech/Pfizer (BNT162b2) and Moderna (Spikevax) have shown high efficacy in clinical trials and real-world-data $(1,2)$. Until now, real-world-data regarding the persistence of the induced humoral and especially cellular immune response post-vaccination are rare.

Even in short-term studies, elderly people were reported to have a less intense immune response after two doses of the BioNTech/Pfizer vaccine BNT162b2 $(3,4)$. This was also seen in patients under immunosuppression, such as after organ transplantation (5).

Initial studies reported a decrease in antibodies after 6 months $(4,6)$ or a correlating increased number of infections after complete vaccination (7); but data regarding the longitudinal serological dynamics of immunization after BNT162b2 vaccine is limited.

In this trial we report the mid-term dynamics of immune response, 9 months after second dose of BNT162b2, by determining anti-SARS-CoV-2-immunglobulin G (IgG) antibodies, T-cell-response and neutralizing antibodies. The study cohort consisted of a well-defined group of health care employees, known to be under a higher risk for COVID-19.

\section{METHODS}

\section{Study Design}

In April 2020 we initiated a longitudinal study in health care workers measuring sero-epidemiological data during the COVID-19 pandemic (8). All employees of the secondary care hospital located in the province of Schleswig-Holstein near the border of the city of Hamburg in Northern Germany were invited to participate. All employees were offered vaccination against SARS-CoV-2 starting in December 2020. In April 2021, all participants were invited to provide a blood specimen to evaluate the antibody prevalence after vaccination or infection (9).

For this study, an additional analysis of all participants around 9 months after second dose of BioNTech/Pfizer vaccine was made to evaluate the longitudinal persistence of the vaccineinduced immune response.

All blood samples were collected on November $13^{\text {th }}-14^{\text {th }}$ 2021 and all participants were asked to complete an additional questionnaire, regarding post-vaccination reactions and previous SARS-CoV-2 infections.

All participants provided written and informed consent prior to enrolment. This study was prospectively registered at the German Clinical Trial Register (DRKS00021270) after approval by the Ethics Committee of the Medical Association SchleswigHolstein. All study activities were conducted in accordance with the Declaration of Helsinki.

\section{Anti-SARS-CoV-2-IgG Antibodies}

The fully automated semiquantitative anti-SARS-CoV-2-ELISA (IgG) from Euroimmun (Lübeck, Germany) was used to detect the S1 domain of the SARS-CoV-2 spike-protein. In accordance to the manufacturer this test shows a specificity of $99.0 \%$ and sensitivity of $93.8 \%$ (10). As this was the same test used within the previous analyses, a longitudinal comparability was ensured. This ELISA calculates a ratio of the extinction of patient sample over the extinction of the calibrator and therefor no unit is used. A ratio below 0.8 was considered negative, a ratio $\geq 0.8$ to $<1.1$ was considered equivocal, and a ratio $\geq 1.1$ was considered positive as defined by the manufacturer.

In addition, a fully automated quantitative anti-SARS-CoV-2assay (IgG) from Abbott (Chicago, USA) was performed. In keeping with the $\mathrm{WHO}$-standard, data were expressed in Binding Antibody Units per $\mathrm{ml}(\mathrm{BAU} / \mathrm{ml})$. Samples were marked seronegative below $7.1 \mathrm{BAU} / \mathrm{ml}$ whereas values above 7.1 $\mathrm{BAU} / \mathrm{ml}$ were determined to be positive, as mentioned by the manufacturer.

\section{Neutralizing Antibodies Against SARS-CoV-2}

All samples were analyzed for neutralizing anti-SARS-CoV-2 antibodies using the NeutraLISA ${ }^{\mathrm{TM}}$ SARS-CoV-2 Neutralization Antibody Detection KIT (Euroimmun, Lübeck, Germany) in accordance to the manufacturer's instructions. Binding inhibition values above $35 \%$ were considered positive, whereas values between $20 \%$ and $35 \%$ were considered equivocal.

\section{T-Cell-Response}

Cellular immunity to SARS-CoV-2 was assessed by using an Interferon (IFN)-gamma release assay (IGRA) from Euroimmun (Quan-T-cell SARS-CoV-2 kit). The assay was performed according to manufacturer's instructions. In brief, $500 \mu \mathrm{l}$ of heparinized blood was stimulated with SARS-CoV-2 specific peptides covering regions of the viral S1-domain. After incubating the tubes $\left(37^{\circ} \mathrm{C}, 22 \mathrm{~h}\right)$, plasma was collected and tested for Interferon-gamma release using an ELISA-assay (Quan T-cell ELISA, Euroimmun). Background IFN-gamma values were assessed by incubating blood without prior peptidestimulation. As a positive control, blood cells were stimulated with mitogen, resulting in a broad and unspecific IFN-gamma secretion. IFN-gamma concentration was expressed as $\mathrm{mIU} / \mathrm{ml}$. Values $>200 \mathrm{mIU} / \mathrm{ml}$ were considered positive, whereas values between 100-200 $\mathrm{mIU} / \mathrm{ml}$ were considered equivocal.

\section{Statistical Analysis}

IBM SPSS Statistics Version 25 (IBM Co., Armonk, NY, USA) was used for statistical analysis. Graphics were elaborated using IBM SPSS Statistics Version 25 (IBM Co., Armonk, NY, USA) and GraphPad Prism 9.

All variables are presented as means with standard deviation. Categorical variables are shown as numbers with percentages. Fisher's exact test or chi-square test was used to determine relationships between categorical variables depending on size of groups. Exact 95\% confidence intervals were provided where 
appropriate. Differences between groups were analyzed using Wilcoxon test. Inter-group differences were analyzed using MannWhitney-U test or Kruskal-Wallis-test. A linear regression analysis was done to investigate the joint effect of age, sex, body mass index and current smoking on antibody and $\mathrm{t}$-cell response using the backward selection method. The t-cell response had a skewed distribution and was logarithmized for the regression analysis. A p-value $<0.05$ was considered statistically significant.

\section{RESULTS}

A total of 184 participants provided a blood sample 9 months (range 7-9 months) after receiving their second dose of BioNTech/Pfizer. This meant a follow-up rate of $58.41 \%$ compared to the analysis after the second dose of vaccine (315 participants in April 2021) (9).

In this follow-up, the study characteristics did not differ significant to the previous follow-ups with $73.4 \%$ female and $26.6 \%$ male and a mean age of $46.32 \pm 10.91$ years. 3 participants reported a previous SARS-CoV-2 infection. Of these, 1 was reported prior to vaccination, and 2 cases occurred between the second dose of vaccine and this follow-up (Table 1). These participants are included in the following analysis.

\section{Anti-SARS-CoV-2-IgG}

In the previous analysis, all participants showed a positive antibody-ratio after two doses of BioNTech/Pfizer, whereas two participants seroconverted to an equivocal result in this follow-up after 9 months. The antibody-ratio was significantly lower in the follow-up analysis after 9 months $(8.01 \pm 1.00$. vs. $3.84 \pm 1.69 ; \mathrm{p}<0.001)$ (Figure 1).

The mean reduction of the IgG antibody-ratio was $53.11 \% \pm 17.95 \%$.

In order to further improve the assessment of the humoral immune response, quantification of anti-SARS-CoV-2 antibodies was performed according to $\mathrm{WHO}$ standards (BAU/ml). All participants showed antibody levels above the manufacturer's cutoff (mean: $124.67 \pm 104.41 \mathrm{BAU} / \mathrm{ml}$ ) (Figure 2).

\section{Neutralizing Antibodies}

Overall, 96\% of study-participants showed neutralizing antibodies against SARS-CoV-2. Our data show a mean binding inhibition capability of $68.20 \% \pm 18.87 \% 9$ months after the second vaccination using BioNTech/Pfizer vaccine (Figure 3).

\section{T-Cell Response}

9 months after the second dose of the BioNTech/Pfizer vaccine, $73.4 \%$ of participants had a detectable T-cell-immune response. There was no significant correlation of the positivity in relation to the sex, obesity or smoking behavior. The mean IFN-gamma concentration was $579.68 \mathrm{mlU} / \mathrm{ml} \pm 705.56 \mathrm{mlU} / \mathrm{ml}$ within this study cohort (Figure 4).

We identified several factors associated with a lower T-cell response and a lower level of neutralizing antibodies (Table 2). A BMI above $30(p=0.004)$ and smoking $(p=0.034)$ was associated with a reduced level of neutralizing antibodies. The distribution of sex $(p=0.656)$ and age $(p=0.135)$ did not differ significantly in the group of obese participants. This was also seen for the group of smoking participants with a mean age of $46.36 \pm 10.80$ years (sex: $\mathrm{p}=0.854$; age: $\mathrm{p}=0.739$ ). Male participants showed a lower $\mathrm{T}$-cell response at this timepoint, whereas this difference remained insignificant following the Mann-Whitney-U-test.

During the 9 months follow-up period, the antibody-ratio showed a significant decrease in older participants $(p=0.003$ following the Kruskal-Wallis-test) (Figure 5A).

There was also a statistically significant decrease in neutralizing antibodies ( $p=0.001$ ) (Figure 5B), but the reduction in INFgamma-level remained statistically insignificant $(\mathrm{p}=0.218)$.

Comparing the cellular and humoral immune response, we could not find a significant correlation between these two (Figure 6).

The additionally performed linear regression analysis confirmed the univariate analyses regarding the differences in persisting immune response after 9 months. A significant negative effect on antibody persistence was observed for older $(\mathrm{p}<0.001)$ and obese $(\mathrm{p}=0.01)$ participants. Smoking had also a negative effect, with $\mathrm{p}$-value slightly above the limit $(\mathrm{p}=0.08)$ Table 3 gives the regression estimates and the corresponding $\mathrm{p}$ values and $95 \%$ confidence intervals. Sex had no effect. The same result was also found for neutralizing antibodies as dependent variable. Table 4 gives the corresponding results. Thus, the estimated neutralizing antibodies value for a nonsmoker, age 50 and BMI 25 is $68.705 \%$.

\section{DISCUSSION}

This study analyzes the persistence of the humoral and cellular response, including neutralizing antibodies, to BioNTech/Pfizer

TABLE 1 | Immune status of previously infected and vaccinated participants in comparison to the mean values of the study cohort.

\begin{tabular}{|c|c|c|c|c|}
\hline Participant & Time since infection [months] & Anti-SARS-CoV-2-IgG [BAU/ml] & Neutralizing antibodies [\%] & Interferon-gamma [mlU/ml] \\
\hline A & 17.5 & 314.40 & 97.26 & 645.60 \\
\hline $\mathrm{B}$ & 8.5 & 304.30 & 96.87 & 170.00 \\
\hline $\mathrm{C}$ & 6.5 & 26.90 & 39.12 & 1216.20 \\
\hline Study cohort & & Anti-SARS-CoV-2-IgG [BAU/ml] (mean \pm SD) & $\begin{array}{l}\text { Neutralizing antibodies [\%] } \\
\qquad(\text { mean } \pm \text { SD) }\end{array}$ & $\begin{array}{l}\text { Interferon-gamma [mlU/ml] } \\
(\text { mean } \pm \text { SD) }\end{array}$ \\
\hline$n=184$ & -- & $124.67 \pm 104.41$ & $68.20 \pm 18.87$ & $579.68 \pm 705.56$ \\
\hline
\end{tabular}

$S D$, standard deviation. 


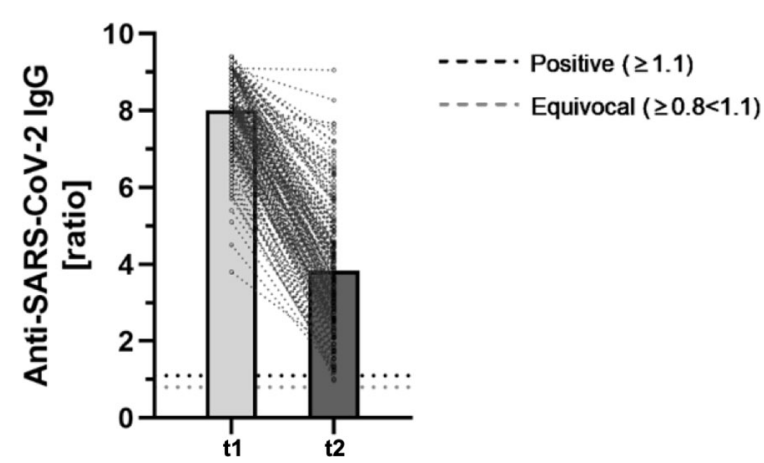

FIGURE 1 | Comparing anti-SARS-CoV-2-IgG ratios 2 months after second BNT162b2-dose (t1) and a mid-term follow-up 9 months after second dose (t2) ( $n=184)$. The fully automated anti-SARS-CoV-2-ELISA from Euroimmun was used to determine semiquantitative IgG-antibody ratios. As defined by the manufacturer, ratios $\geq 1.1$ were considered positive (horizontal black dotted line). Ratios $\geq 0.8<1.1$ were considered equivocal (horizontal gray dotted line).

vaccine in a well-defined group of hospital employees as part of a longitudinal evaluation.

Up until now, little is known about the persistence of the immune response after vaccination with BioNTech/Pfizer. This study reveals a significant antibody decrease in a mid-termfollow-up in all subgroups, affecting especially older people and people with a high BMI.

\section{Immune Response After 9 Months}

Currently there is minimal data about the long-lasting effect following active immunization with mRNA vaccines.

In our cohort, the antibody ratio decreased in the 9-month follow-up to about the half of the initial value. This was not

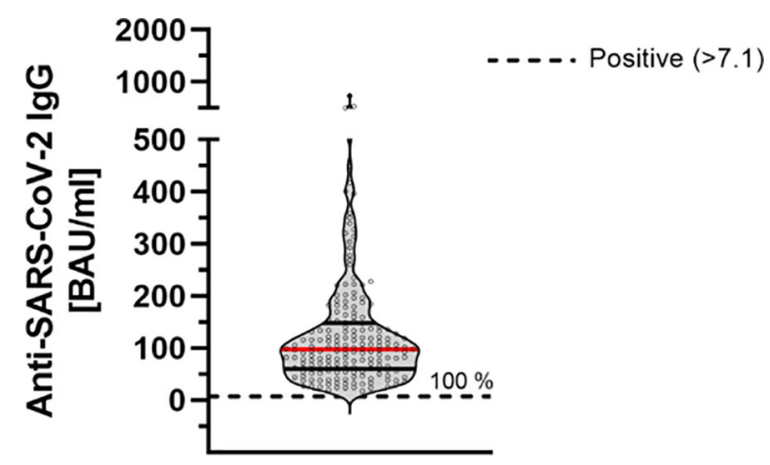

FIGURE 2 | Quantitative determination of anti-SARS-CoV-2-lgG antibodies 9 months after second dose of BNT162b2 $(n=184)$. Anti-SARS-CoV-2-lgG antibodies were determined using a quantitative assay from Abbott. In keeping with the $\mathrm{WHO}$-standard, data were expressed in Binding Antibody Units per $\mathrm{ml}(\mathrm{BAU} / \mathrm{ml})$. Samples were marked seronegative below 7.1 BAU/ml whereas values above 7.1 $\mathrm{BAU} / \mathrm{ml}$ were determined to be positive (horizontal black dotted line), as mentioned by the manufacturer. Red line marks the mean. The dashed gray line marks the positive cutoff specified by the manufacturer.

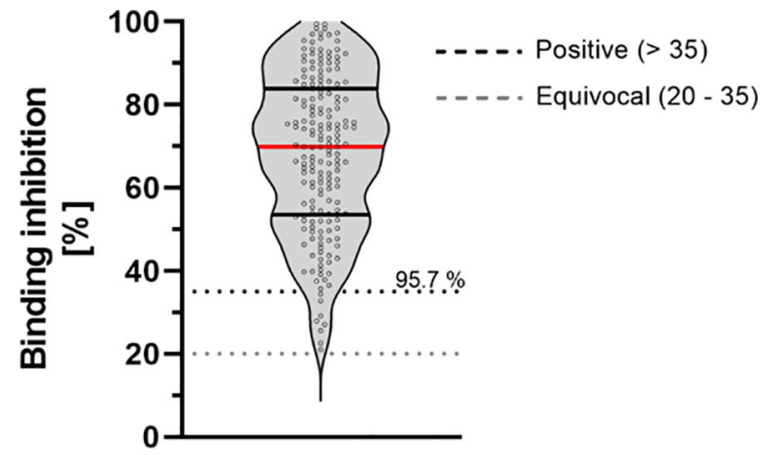

FIGURE 3 | Binding inhibition capability of neutralizing antibodies 9 months after vaccination with BioNTech/Pfizer vaccine BNT162b2. Neutralizing antiSARS-CoV-2 antibodies were determined using the NeutraLISA ${ }^{\text {TM }}$ SARSCoV-2 Neutralization Antibody Detection KIT from Euroimmun. According to the manufacturer, binding inhibition values above 35\% were considered positive (horizontal black dotted line), whereas values between 20\% and 35\% were considered equivocal (horizontal gray dotted line). Red line marks the mean. The dashed lines show the positive (light gray)- and equivocal (dark gray) cutoffs specified by the manufacturer.

surprising, as first half-year follow-ups showed a decrease during that timeframe (4), and it is well known, that not all plasmablasts commit as memory plasma cells $(11,12)$.

The decreased antibody ratio is also detected in the decreased neutralization capacity. Several studies found this decrease to begin as early as 3 months after vaccination $(4,13)$.

Discussing the long-lasting effect of mRNA vaccines (such as the one from BioNTech/Pfizer) in protecting against COVID-19 disease, the role of cellular immunity in addition to humoral response might be important but is often disregarded due to elaborate assays, which are not feasible in standard-laboratories. We determined cellular immunity in a simplified approach by

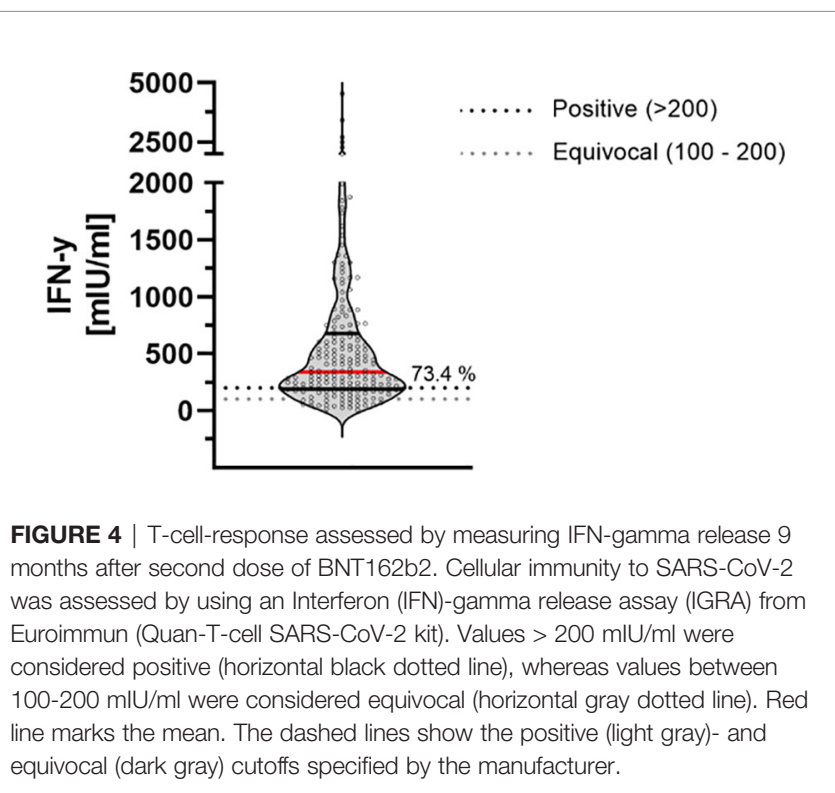


TABLE 2 | Participants 9 months after second dose of BioNTech/Pfizer vaccine $(n=184)$.

\begin{tabular}{|c|c|c|c|c|c|c|c|c|}
\hline & $\begin{array}{c}\text { Antibody ratio after } 9 \\
\text { months, } M \pm S D\end{array}$ & $\begin{array}{c}\mathrm{p}- \\
\text { value }\end{array}$ & $\begin{array}{l}\text { Reduction of initial antibody } \\
\text { response (\%), } M \pm S D\end{array}$ & $\begin{array}{c}\mathrm{p}- \\
\text { value }\end{array}$ & $\begin{array}{c}\text { T-cell } \\
\text { response, } M \pm \\
\text { SD }\end{array}$ & $\begin{array}{c}\mathrm{p}- \\
\text { value }\end{array}$ & $\begin{array}{l}\text { Neutralizing antibodies } \\
(\%), M \pm S D\end{array}$ & $\begin{array}{c}\mathrm{p}- \\
\text { value }\end{array}$ \\
\hline All $(n=184)$ & $3.84 \pm 1.69$ & & $53.11 \pm 17.95$ & & $579.68 \pm 705.56$ & & $68.20 \pm 18.87$ & \\
\hline \multicolumn{9}{|l|}{ Sex } \\
\hline Male $(n=49)$ & $3.84 \pm 1.71$ & $0.938^{a}$ & $52.32 \pm 17.98$ & $0.712^{\mathrm{a}}$ & $492.17 \pm 528.48$ & $0.146^{a}$ & $66.98 \pm 20.93$ & $0.805^{\mathrm{a}}$ \\
\hline Female $(n=135)$ & $3.84 \pm 1.68$ & & $53.39 \pm 18.00$ & & $611.44 \pm 758.94$ & & $68.65 \pm 18.12$ & \\
\hline \multicolumn{9}{|l|}{ Smoking } \\
\hline Yes $(n=52)^{+}$ & $3.45 \pm 1.56$ & $0.062^{\mathrm{a}}$ & $56.80 \pm 16.25$ & $0.120^{a}$ & $512.60 \pm 726.06$ & $0.162^{a}$ & $63.59 \pm 18.84$ & $0.034^{\mathrm{a}}$ \\
\hline No $(n=132)$ & $3.99 \pm 1.72$ & & $51.65 \pm 18.43$ & & $606.10 \pm 698.35$ & & $70.03 \pm 18.64$ & \\
\hline \multicolumn{9}{|l|}{ Obesity } \\
\hline Yes $(n=30)^{\#}$ & $3.19 \pm 1.70$ & $0.012^{\mathrm{a}}$ & $59.16 \pm 18.82$ & $0.020^{\mathrm{a}}$ & $451.80 \pm 475.61$ & $0.306^{a}$ & $58.68 \pm 20.20$ & $0.004^{a}$ \\
\hline No $(n=154)$ & $3.96 \pm 1.66$ & & $51.92 \pm 17.60$ & & $604.58 \pm 740.75$ & & $70.07 \pm 18.09$ & \\
\hline \multicolumn{9}{|l|}{ Age groups } \\
\hline$<30(n=13)$ & $4.92 \pm 1.95$ & $0.003^{b}$ & $42.86 \pm 21.82$ & $0.008^{b}$ & $465.95 \pm 523.68$ & $0.216^{b}$ & $78.60 \pm 19.89$ & $0.001^{b}$ \\
\hline $31-39(n=40)$ & $4.45 \pm 1.66$ & & $46.99 \pm 18.08$ & & $753.12 \pm 980.72$ & & $74.37 \pm 18.62$ & \\
\hline $40-49(\mathrm{n}=57)$ & $3.77 \pm 1.47$ & & $53.58 \pm 16.17$ & & $568.40 \pm 678.75$ & & $69.32 \pm 15.95$ & \\
\hline $50-59(n=47)$ & $3.36 \pm 1.61$ & & $57.65 \pm 16.80$ & & $468.27 \pm 565.18$ & & $62.07 \pm 20.29$ & \\
\hline$>60(n=27)$ & $3.36 \pm 1.75$ & & $58.19 \pm 17.89$ & & $595.19 \pm 549.00$ & & $62.13 \pm 17.48$ & \\
\hline
\end{tabular}

$M$, mean.

$S D$, standard deviation.

a Mann-Whitney-U-test.

${ }^{b}$ Kruskal-Wallis-Test.

+ Including 9 male and 21 female participants.

\#Including 13 male and 39 female participants.

Obesity is defined as a Body mass index above 30.
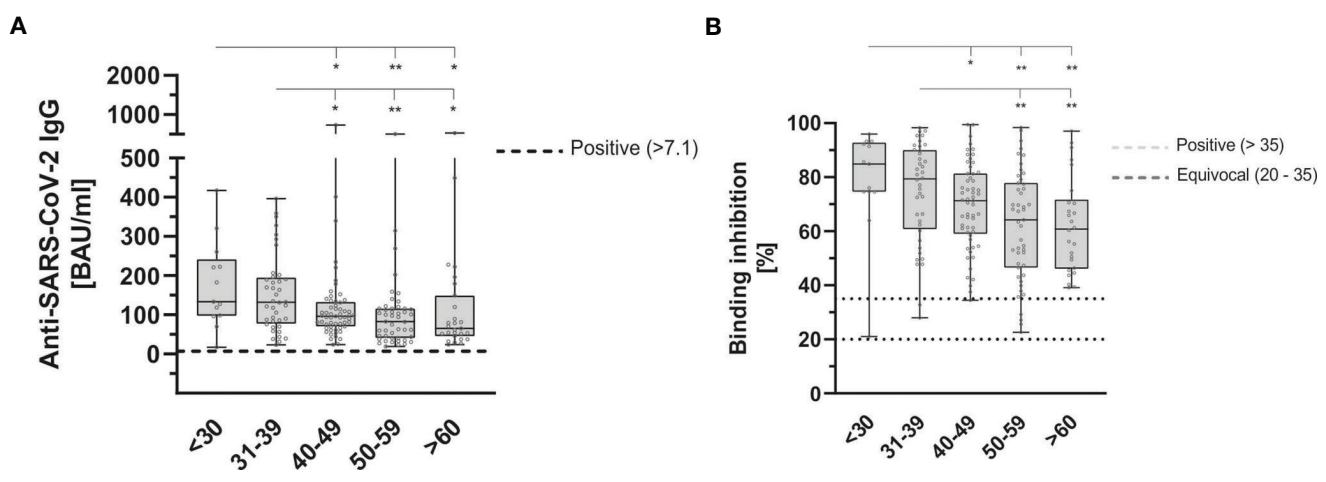

FIGURE 5 | Age dependent anti-SARS-CoV-2-IgG binding antibodies (A) and neutralizing antibodies (B) 9 months after second dose of BioNTech/Pfizer vaccine with both, significantly reduced in older participants ( $p=0.003$ and $p=0.001$, respectively). Anti-SARS-CoV-2-lgG antibodies were determined using a quantitative assay from Abbott. In keeping with the WHO-standard, data were expressed in Binding Antibody Units per $\mathrm{ml}(\mathrm{BAU} / \mathrm{ml})$. Samples were marked seronegative below $7.1 \mathrm{BAU} / \mathrm{ml} \mathrm{whereas} \mathrm{values}$ above 7.1 BAU/ml were determined to be positive (horizontal black dotted line), as mentioned by the manufacturer. Neutralizing anti-SARS-CoV-2 antibodies were determined using the NeutraLISA ${ }^{\text {TM }}$ SARS-CoV-2 Neutralization Antibody Detection KIT from Euroimmun. According to the manufacturer, binding inhibition values above $35 \%$ were considered positive (horizontal black dotted line), whereas values between $20 \%$ and $35 \%$ were considered equivocal (horizontal gray dotted line). Cohorts were grouped as follows (in years): $<30(n=13), 31-39(n=40), 40-49(n=57), 50-59(n=47),>60(n=27) .{ }^{*} p<0.05 ;{ }^{* *} p<0.01$ (Mann-Whitney U-test).

IFN-gamma release after stimulation of blood-cells with specific SARS-CoV-2 peptides.

In our cohort, $73.40 \%$ showed a detectable T-cell response even 9 months after vaccination. This is in line with data presented by Naaber et al. for their 6-months follow-up (4), and in keeping with the initial phase I/II trial showing an activation of T-cells after using mRNA vaccines (14).

Compared to our data, Tober-Lau et al. determined a higher median IFN-gamma release six months after BNT162b2-vaccination within their HCW-cohort using the same IGRA-assay (1198.0 mIU/ml vs. $412.0 \mathrm{mIU} / \mathrm{ml}$ ) (15). In addition, binding inhibition capability of neutralizing antibodies was considerably lower within our cohort $(88.1 \%$ vs. $68.2 \%$ ). Reasons for this may be the different time points of examination after second vaccination ( 9 vs. 6 months) and the higher average age of our cohort (46 vs 35 years). Referring to the same kits used the decreasing immune response was also seen in reconvalescent patients, whereas the authors only have reported the positivity rate instead of the values measured (16). 


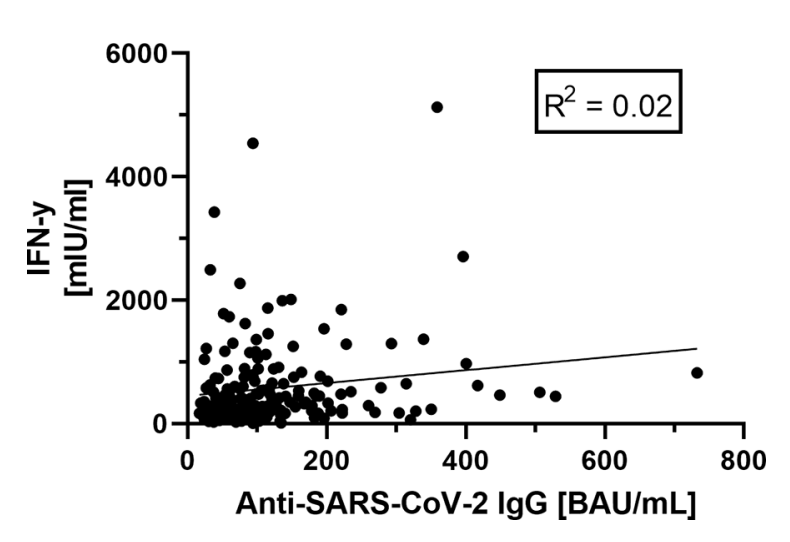

FIGURE 6 | Correlation between humoral (anti-SARS-CoV-2-IgG antibodies)and cellular (Interferon-gamma release) immunity. No correlation between humoral and cellular immunity values could be shown $\left(R^{2}=0.02\right)$, based on the data shown before.

\section{Factors Associated With a Reduced Immune Response to SARS-CoV-2}

In our follow-up study, we found a correlation between age, obesity and smoking with respect to almost all considered immune responses.

As shown in previous studies, we confirmed the negative correlation between antibody responses and the age of vaccinated individuals $(3,4)$. In addition to the reduced antibody response after vaccination older people are known to have a faster decrease after vaccination (4). Interestingly, obese participants with a BMI higher than 30 showed a significantly higher decrease in the antibody ratio and also significantly lower neutralizing antibodies not only in the univariate analysis but also following the regression analysis. This effect was first described by Watanabe et al. (17) and seen by Malavazos et al. (18) in the first months after vaccination.
The effect of smoking immediately after vaccination was already discussed $(9,17)$ and is reported to influence the effectiveness of other vaccines due to a general immunosuppression caused by smoking $(17,19)$. In this 9 -month evaluation, for the only significant difference was with respect to neutralizing antibodies.

These findings are important as obese people and elderly are known to have a higher risk not only for SARS-CoV-2 infection, but especially for a severe course of COVID-19 (20,21). Further studies are needed to evaluate the longitudinal course of cellular and humoral immune response not only after two doses of BioNTech/Pfizer but also after a third dose.

\section{Limitation}

The major limitation of this trial is its single-center design. Due to the inclusion of hospital employees, women are relatively overrepresented and other groups with a higher risk are underrepresented. Especially elderly participants, with an age over 70 years, are not included in this study.

It cannot be excluded that there were asymptomatic, undetected SARS-CoV-2 infections among the participants during the 9 months after second vaccination, which may lead to a slight bias in the results.

Further differentiations concerning the humoral immune response (such as IgG subclasses or antibody glycosylation patterns) or the cellular immune response (e.g. distinguishing between CD4 and CD8 T-cells) could provide further important aspects. However, these analyses should be carried out by specialized working groups.

Due to the use of different methods, it was not possible to compare the absolute values of antibody concentrations, T-cell responses or neutralizing antibodies over the follow-up-period. Therefore, a convincing calculation of the half-life of the immune response is not possible.

Further evaluations of antibody response after vaccination are needed, to investigate the longitudinal persistence of antibodies and the possible need for further booster vaccinations.

TABLE 3 | Linear regression for Anti-SARS-CoV-2 antibody ratio as dependent variable and smoking, age and BMl as covariable.

\begin{tabular}{|c|c|c|c|c|}
\hline Variable & & Parameter Estimate & $p$-value & $95 \% \mathrm{Cl}$ \\
\hline (Intercept) & $\alpha$ & 1.249 & $<0.001$ & (1.168, 1.329) \\
\hline $\mathrm{BMl}-25^{*}$ & $\beta_{1}$ & -0.0182 & 0.01 & $(-0.032,-0.0043)$ \\
\hline Current smoking (yes) & $\beta_{2}$ & -0.128 & 0.08 & $(-0.273,0.017)$ \\
\hline Age $-50^{\star}$ & $\beta_{3}$ & -0.0115 & $<0.001$ & $(-0.0175,-0.00544)$ \\
\hline
\end{tabular}

Cl, confidence interval; BMI, body mass index.

$R^{2}=0.13$

*linear transformation of BMI (minus 25) and Age (minus 50).

TABLE 4 | Linear regression for neutralizing antibodies as dependent variable and smoking, age and BMI as covariable.

\begin{tabular}{|c|c|c|c|c|}
\hline Variable & & Parameter Estimate & p-value & $95 \% \mathrm{Cl}$ \\
\hline (Intercept) & $\alpha$ & 68.705 & $<0.001$ & $(65.47,71.94)$ \\
\hline $\mathrm{BMI}-25^{\star}$ & $\beta_{1}$ & -0.687 & 0.02 & $(-1.24,-0.13)$ \\
\hline Current smoking (yes) & $\beta_{2}$ & -5.51 & 0.06 & $(-11.32,0.303)$ \\
\hline Age $-50^{\star}$ & $\beta_{3}$ & -0.423 & $<0.001$ & $(-0.665,-0.180)$ \\
\hline
\end{tabular}

$\mathrm{Cl}$, confidence interval; BMI, body mass index.

$R^{2}=0.13$

*linear transformation of BMI (minus 25) and Age (minus 50). 


\section{CONCLUSION}

This study showed an age-dependent decrease of vaccineinduced anti-SARS-CoV-2-IgG antibodies in a midtermfollow-up after 9 months. People with a higher risk for a severe COVID-19-disease course, such as elderly or obese people, showed a reduced immune response at this timepoint after vaccination. These results encourage the use, and need, of so-called booster doses 6 months after the second dose of the BioNTech/Pfizer vaccine BNT162b2, especially in vulnerable individuals such as elderly or obese people.

\section{DATA AVAILABILITY STATEMENT}

The raw data supporting the conclusions of this article will be made available by the authors on reasonable request, without undue reservation.

\section{ETHICS STATEMENT}

The studies involving human participants were reviewed and approved by Ethics Committee of the Medical Association

\section{REFERENCES}

1. Pawlowski C, Lenehan P, Puranik A, Agarwal V, Venkatakrishnan AJ, Niesen MJM, et al. FDA-Authorized mRNA COVID-19 Vaccines are Effective Per Real-World Evidence Synthesized Across a Multi-State Health System. Med (2021) 2:979-992.e8. doi: 10.1016/j.medj.2021.06.007

2. Thompson MG, Burgess JL, Naleway AL, Tyner HL, Yoon SK, Meece J, et al. Interim Estimates of Vaccine Effectiveness of BNT162b2 and mRNA-1273 COVID-19 Vaccines in Preventing SARS-CoV-2 Infection Among Health Care Personnel, First Responders, and Other Essential and Frontline Workers - Eight U.S. Locations, December 2020-March 2021. MMWR Morb Mortal Wkly Rep (2021) 70:495-500. doi: 10.15585/mmwr.mm7013e3

3. Müller L, Andrée M, Moskorz W, Drexler I, Walotka L, Grothmann R, et al. AgeDependent Immune Response to the Biontech/Pfizer BNT162b2 COVID-19 Vaccination. Clin Infect Dis (2021) 73:2065-72. doi: 10.1093/cid/ciab381

4. Naaber P, Tserel L, Kangro K, Sepp E, Jürjenson V, Adamson A, et al. Dynamics of Antibody Response to BNT162b2 Vaccine After Six Months: A Longitudinal Prospective Study. Lancet Reg Heal Eur (2021) 10:100208. doi: 10.1016/j.lanepe.2021.100208

5. Schramm R, Costard-Jäckle A, Rivinius R, Fischer B, Müller B, Boeken U, et al. Poor Humoral and T-Cell Response to Two-Dose SARS-CoV-2 Messenger RNA Vaccine BNT162b2 in Cardiothoracic Transplant Recipients. Clin Res Cardiol (2021) 110:1142-9. doi: 10.1007/s00392-021-01880-5

6. Tartof SY, Slezak JM, Fischer H, Hong V, Ackerson BK, Ranasinghe ON, et al. Effectiveness of mRNA BNT162b2 COVID-19 Vaccine Up to 6 Months in a Large Integrated Health System in the USA: A Retrospective Cohort Study. Lancet (London England) (2021) 398:1407-16. doi: 10.1016/S0140-6736(21) 02183-8

7. Keehner J, Horton LE, Binkin NJ, Laurent LC, Pride D, Longhurst CA, et al. Resurgence of SARS-CoV-2 Infection in a Highly Vaccinated Health System Workforce. N Engl J Med (2021) 385:1330-2. doi: 10.1056/NEJMc2112981

8. Herzberg J, Vollmer T, Fischer B, Becher H, Becker A-K, Sahly H, et al. A Prospective Sero-Epidemiological Evaluation of SARS-CoV-2 Among Health Care Workers in a German Secondary Care Hospital. Int J Infect Dis (2021) 102:136-43. doi: 10.1016/j.ijid.2020.10.026

9. Herzberg J, Vollmer T, Fischer B, Becher H, Becker A-K, Honarpisheh H, et al. SARS-CoV-2-Antibody Response in Health Care Workers After
Schleswig-Holstein. The participants provided their written informed consent to participate in this study.

\section{AUTHOR CONTRIBUTIONS}

$\mathrm{JH}$ and $\mathrm{BF}$ conducted the research and wrote the manuscript. These authors contributed equally to this research. $\mathrm{CL}$ and $\mathrm{BF}$ performed the assays. HB supervised the statistical analysis. A$\mathrm{KB}, \mathrm{HH}$, and SG reviewed the manuscript. TS initiated the research and supervised the study. TS and CK reviewed the final draft of this article and provided logistic support. All authors have critically reviewed and approved the final draft and are responsible for the content of the manuscript.

\section{ACKNOWLEDGMENTS}

We would like to thank all team members at the Krankenhaus Reinbek St. Adolf-Stift, and all participating laboratories that analyzed these additional samples in a phase of high workload. Thanks also to Rebecca Zimmer (linguistic enrichment) for her intense and rapid help.

Vaccination or Natural Infection in a Longitudinal Observational Study. Vaccine (2022) 40:206-12. doi: 10.1016/J.VACCINE.2021.11.081

10. Okba NMA, Müller MA, Li W, Wang C, GeurtsvanKessel CH, Corman VM, et al. Severe Acute Respiratory Syndrome Coronavirus 2-Specific Antibody Responses in Coronavirus Disease Patients. Emerg Infect Dis (2020) 26:147888. doi: 10.3201/eid2607.200841

11. Khodadadi L, Cheng Q, Radbruch A, Hiepe F. The Maintenance of Memory Plasma Cells. Front Immunol (2019) 10:721. doi: 10.3389/fimmu.2019.00721

12. Quast I, Tarlinton D. B Cell Memory: Understanding COVID-19. Immunity (2021) 54:205-10. doi: 10.1016/j.immuni.2021.01.014

13. Souza WM, Amorim MR, Sesti-Costa R, Coimbra LD, Brunetti NS, ToledoTeixeira DA, et al. Neutralisation of SARS-CoV-2 Lineage P.1 by Antibodies Elicited Through Natural SARS-CoV-2 Infection or Vaccination With an Inactivated SARS-CoV-2 Vaccine: An Immunological Study. Lancet Microbe (2021) 2:e527-35. doi: 10.1016/S2666-5247(21)00129-4

14. Sahin U, Muik A, Derhovanessian E, Vogler I, Kranz LM, Vormehr M, et al. COVID-19 Vaccine BNT162b1 Elicits Human Antibody and TH1 T Cell Responses. Nature (2020) 586:594-9. doi: 10.1038/s41586-020-2814-7

15. Tober-Lau P, Schwarz T, Vanshylla K, Hillus D, Gruell H, Group ES, et al. Long-Term Immunogenicity of BNT162b2 Vaccination in the Elderly and in Younger Health Care Workers. medRxiv (2021) 2021.08.26.21262468. doi: 10.1101/2021.08.26.21262468

16. Schiffner J, Backhaus I, Rimmele J, Schulz S, Möhlenkamp T, Klemens JM, et al. Long-Term Course of Humoral and Cellular Immune Responses in Outpatients After SARS-CoV-2 Infection. Front Public Heal (2021) 9:732787. doi: 10.3389/fpubh.2021.732787

17. Watanabe M, Balena A, Tuccinardi D, Tozzi R, Risi R, Masi D, et al. Central Obesity, Smoking Habit, and Hypertension are Associated With Lower Antibody Titres in Response to COVID-19 mRNA Vaccine. Diabetes Metab Res Rev (2022) 38:e3465. doi: 10.1002/dmrr.3465

18. Malavazos AE, Basilico S, Iacobellis G, Milani V, Cardani R, Boniardi F, et al. Antibody Responses to BNT162b2 mRNA Vaccine: Infection-Naïve Individuals With Abdominal Obesity Warrant Attention. Obes (Silver Spring) (2021). doi: 10.1002/oby.23353

19. Winter AP, Follett EAC, McIntyre J, Stewart J, Symington IS. Influence of Smoking on Immunological Responses to Hepatitis B Vaccine. Vaccine (1994) 12:771-2. doi: 10.1016/0264-410X(94)90283-6 
20. Nakeshbandi M, Maini R, Daniel P, Rosengarten S, Parmar P, Wilson C, et al. The Impact of Obesity on COVID-19 Complications: A Retrospective Cohort Study. Int J Obes (Lond) (2020) 44:1832-7. doi: 10.1038/s41366-0200648-x

21. Stanetić K, Stanetić B, Petrović V, Marković B, Kević V, Todorović N, et al. The Influence of Different Risk Factors on COVID-19 Outcomes in Adult Patients - An Observational-Descriptive Study. Acta Med Acad (2021) 50:308-16. doi: 10.5644/ama2006-124.348

Conflict of Interest: The authors declare that the research was conducted in the absence of any commercial or financial relationships that could be construed as a potential conflict of interest.
Publisher's Note: All claims expressed in this article are solely those of the authors and do not necessarily represent those of their affiliated organizations, or those of the publisher, the editors and the reviewers. Any product that may be evaluated in this article, or claim that may be made by its manufacturer, is not guaranteed or endorsed by the publisher.

Copyright (๑) 2022 Herzberg, Fischer, Lindenkamp, Becher, Becker, Honarpisheh, Guraya, Strate and Knabbe. This is an open-access article distributed under the terms of the Creative Commons Attribution License (CC BY). The use, distribution or reproduction in other forums is permitted, provided the original author(s) and the copyright owner(s) are credited and that the original publication in this journal is cited, in accordance with accepted academic practice. No use, distribution or reproduction is permitted which does not comply with these terms. 